\section{CORONARY SINUS REDUCER STENT}

\section{To the Editor:}

I read with great interest the article by Guenter Weigel and colleagues. ${ }^{1}$ I want to commend the authors for their great effort to understand the cascade of molecular events leading to neovascularization in coronary sinus interventions. However, I would like to add some comments.

The term "Beck procedure" alone is a nonspecific term inasmuch as $\mathrm{Dr}$ Claude Beck has described two types of coronary sinus interventions. ${ }^{2-4}$ The first one, the Beck I procedure, consisted of narrowing the coronary sinus to a diameter of $3 \mathrm{~mm}$, abrading both the epicardium and inner pericardium, spilling of powdered asbestos and $5 \%$ aqueous trichloracetic acid on the epicardium, and placement of mediastinal fat over the treated epicardium. The second, the Beck II procedure, consisted of a vascular graft between the descending aorta and the coronary sinus followed by operative constriction of the coronary sinus ostium a few weeks later. However, both of these procedures have very little in common with pressurecontrolled intermittent coronary sinus occlusion (PICSO), which was studied by the authors.

PICSO has more in common with the coronary sinus reducer stent (CSRS) that was developed as an alternative treatment for patients with refractory angina pectoris. ${ }^{5}$ The CSRS

\footnotetext{
The Editor welcomes submissions for possible publication in the Letters to the Editor section that consist of commentary on an article published in the Journal or other relevant issues. Authors should: • Include no more than 500 words of text, three authors, and five references. - Type with double-spacing. - See http://jtcs.ctsnetjournals.org/misc/ifora.shtml for detailed submission instructions. - Submit the letter electronically via jtcvs.editorialmanager.com. Letters commenting on an article published in the JTCVS will be considered if they are received within 6 weeks of the time the article was published. Authors of the article being commented on will be given an opportunity of offer a timely response ( 2 weeks) to the letter. Authors of letters will be notified that the letter has been received. Unpublished letters cannot be returned.
}

is a balloon-expandable stent that reduces the coronary sinus diameter to $3 \mathrm{~mm}$. It is introduced into the coronary sinus via the venous system, using a percutaneous approach. Fifteen patients with severe angina pectoris have already been successfully treated by this technology. ${ }^{5}$

Personally, I had the opportunity to invent the Neovasc Reducer in the mid-1990s and to lead its initial development team until 2002. The primary idea was to increase a stenotic coronary artery perfusion pressure by limiting its outflow. In other words, if we cannot increase the coronary input, let's limit or decrease its output; instead of manipulating the coronary arteries, let's treat the coronary veins - the upside-down strategy. However, even our first study in nonischemic pigs revealed that 8 to 12 weeks of coronary sinus narrowing ended up with macroscopic epicardial new blood vessels-neovascularization. This was also seen intramyocardially. On those days, the cascade leading from coronary sinus narrowing to new macroscopic epicardial and intramyocardial blood vessels was not clear enough and some explanations other than neovascularization were suggested. The current study by Guenter Weigel and colleagues sheds some light on this subject by favoring the neoangiogenesis explanation that is triggered by some kind of increased coronary sinus pressure.

Werner Mohl, MD, PhD Stefan Mina, BME Dejan Milansinovic Hirofumi Kasahara, $M D, P h D$ Paz Yoav, MD, MHA Hadassah-Hebrew University Medical Center, Department of Cardiothoracic Surgery Hadassah Jerusalem, Israel

\section{References}

1. Weigel G, Kajgana I, Bergmeister H, Riedl G, Glogar HD, Gyöngyösi M, et al. Beck and back: a paradigm change in coronary sinus interventions- pulsatile stretch on intact coronary venous endothelium. J Thorac Cardiovasc Surg. 2007;133:1581-7.

2. Edmunds LH. Cardiac surgery in the adults. New York: McGraw-Hill; 1997. p. 482.

3. Beck C. The coronary operation. Am Heart J. 1941; 22:539.

4. Beck C, Stanton E, Batinchok W, Leiter E. Revascularization of heart by graft of systemic artery. JAMA. 1948;137:436.

5. Banai S, Ben Muvhar S, Parikh KH, Medina A, Sievert H, Seth A, et al. Coronary sinus reducer stent for the treatment of chronic refractory angina pectoris: a prospective, open-label, multicenter, safety feasibility first-in-man study. J Am Coll Cardiol. 2007;49:1783-9.

\section{doi:10.1016/j.jtcvs.2008.01.047}

\section{SINGLE-STAGE VERSUS \\ 2-STAGE REPAIR OF COARCTATION OF THE AORTA WITH VENTRICULAR SEPTAL DEFECT}

\section{To the Editor:}

We read with interest the article by Walters and colleagues ${ }^{1}$ on single- versus 2-stage repair of coarctation (CoA) with ventricular septal defect (VSD) and congratulate the authors for excellent outcomes in patients undergoing single-stage repair of both lesions. However, we would be very cautious in adopting this strategy just because it has been shown to be technically feasible and equally effective in the authors' experience. As the authors have acknowledged themselves, the study population comprises patients spread over a long time frame. We may understand here that when the surgical protocols were developing at the authors' institution, the authors may have elected for a 2-stage approach over a 1-stage approach. As the protocols may have evolved, they were able to make this shift in strategy. However, what prompted them to perform only CoA repair combined with arch augmentation on cardiopulmonary bypass (CPB) and circulatory arrest leaving the VSD open in 3 of their patients is unclear.

An important factor to be considered in developing countries is the morbidity and the costs of the procedure the patients undergo. ${ }^{2}$ Group 1 patients had a prolonged course in 